\title{
Evaluation of isometric strength in people with spinal cord injury: a review
}

\author{
Jamile Ada Nascimento de Lima', Saulo Fernandes Melo de Oliveira², Lúcia Inês Guedes Leite de Oliveira³, \\ Manoel da Cunha Costa ${ }^{4}$
}

\begin{abstract}
Introduction: isometric muscle strength in people with spinal cord injury is usually associated with locomotor activity, posture maintenance and activities of daily living. However, the variety of methods available for the evaluation hinders decision making on the part of the professionals involved. Objective: our objective was to review the literature of the area and determine the evaluation methods of isometric force and relationships with other components of health and physical fitness of people with spinal cord injury (SCI). Methods: consulted if the sites BIREME-Medline and SciELO, under the terms "spinal cord injury", "paraplegia", "tetraplegia", "wheelchair athletes" and "disabilities athletes," "isometric strength", "handgrip" and " handheld "with the help of the Boolean AND operator. Results: they were found 18 studies that met the inclusion criteria. The equipment available, the manual dynamometer is the most used. Sophisticated equipment can evaluate force components with increased functionality. There were no significant changes in hemodynamic variables during isometric strength tests. In conclusion, good isometric strength levels appear to correlate with increased functionality of people with $\mathrm{SCl}$. Conclusion: however, they are lacking reference values related to the isometric strength for this population, especially when tested handgrip.
\end{abstract}

Key words: Muscular strength. Physical activity. People with disabilities.

\section{INTRODUCTION}

Spinal cord injury $(\mathrm{SCl})$ results in the loss of the somatic and autonomic function of the nervous system. The higher (height) and complete the lesion, the greater the loss of function. ${ }^{(1)}$ Thus, injuries to the cervical region until the 1st thoracic vertebra (T1) undertake both the movement as the sensitivity of the four limbs and trunk, while the injury to the thoracic level (from the 2nd thoracic vertebra, T2) compromise the lower limbs and the lower trunk. ${ }^{(2)}$

Immediately after injury there is a decrease in the ability to recruit some muscles such as the rectus abdominis, transverse abdominis, external and internal oblique, quadratus lumborum muscle, and paraspinal muscles. This interruption may lead to compensatory strategies using the non-postural muscles including the large dorsal, trapezius, pectoralis major and neck. Non-traumatic SCls may result from other etiologic origins such as vascular insufficiency, infections, malignant and benign tumors, spinal stenosis, and transverse myelitis. ${ }^{(2)}$

People with $\mathrm{SCl}$ who depend on manual wheelchairs for mobility and for daily activities have shoulder joints as the main load bearing structures, although the shoulder architecture has not been designed for the tasks required in daily activities. ${ }^{(3)}$
Pain in the shoulder assaults approximately $30 \%$ to $50 \%$ of the population with quadriplegia. ${ }^{(4,5)}$ Wheelchair users have a higher prevalence of joint diseases due to dependent overuse of the shoulder function to transfer and to drive the wheelchair. ${ }^{(6)}$ These activities have a muscle requirement of about $50 \%$ of a repetition maximum (1RM), and these repeated high loads may lead to the development of upper limb pain. ${ }^{(6)}$

During inpatient rehabilitation, the levels of physical activity may improve, however, soon after the exit of such programs these levels tend to decrease. Physical fitness in a person with $\mathrm{SCl}$ is usually lower, and impacts on an increased risk of cardiovascular disease; however, for this population it is known that physical activity has a positive effect on health. ${ }^{(7)}$ People with $\mathrm{SCl}$ have to face many obstacles to the realization of physical activity. Hence the necessity to reinforce the role of physical exercise as a preventive strategy, which may reduce health costs and provide a longer life expectancy. ${ }^{(1,8)}$

Components of health-related physical fitness (such as strength, flexibility, and aerobic capacity) are commonly used to assess and control rehabilitation and fitness programs. One of these components, the isometric force (maximum and

\footnotetext{
Corresponding author: Saulo Fernandes Melo de Oliveira. Rua Alto do Reservatório, s/nº Bela Vista, Vitória de Santo Antão, PE. CEP: 55608-680.

${ }^{2}$ Master in Physical Education, professor of the Nucleus of Physical Education and Sports Sciences, Universidade Federal de Pernambuco, Recife (PE), Brazil.
} 
submaximal), is characterized by the ability of the muscle to develop active tension, without angular displacement of the joint, to produce force and/or movement. ${ }^{(9)}$ The muscle power is the produced work rate as a function of time, and may be calculated by multiplying the force by the speed. ${ }^{(10,11)}$ Isometric muscle contractions are those which have a constant length or static contraction, shortening zero speed. ${ }^{(9-11)}$ Among the various forms of muscle contraction, the isometric types are related to the functional aspects of balance, the sitting posture and functionality of people with $\mathrm{SCl}$. ${ }^{(12)}$

Considering the considerable importance given to strength for daily activities, its evaluation, as well as the determination of parameters correlated especially to the quality of life, they are crucial factors for the qualification of the professionals which work with people with $\mathrm{SCl}$. Regarding the evaluation, numerous methodologies and technologies are available in the scientific environment. ${ }^{(9)}$ However, the choice of the most reliable equipment and techniques is extremely important for the diagnosis and decision-making by health professionals. Reliable measures of muscle strength are required to determine the mobility and self-care capacity in people with $\mathrm{SCl}$. Muscle strength tests are used to document the recovery or loss of motor function in people with $\mathrm{SCl}$ and also the best functional assessment at the beginning of force treatment for these individuals.

Although there is a consensus that in rehabilitation programs for people with $\mathrm{SCl}$, it is necessary to include muscular strength training components, by the great possibility of strength applications, the several evaluation methods and equipment available, more precise information about better evaluation strategies and their physiological repercussions, are still scarce. In this sense, the aim of this investigation was to review the existing literature regarding the evaluation of isometric strength in people with $\mathrm{SCl}$; in addition, we aim to verify the relationships between isometric strength and other components of health and physical fitness.

\section{METHODS}

\section{Search and strategy}

This research was characterized as a review with a systematic approach and was divided into three stages. In the first, an evaluator (JL) carried out the search directly on the website of the selected databases (BIREME-Medline and SciELO). The terms used to search were "spinal cord injury", "paraplegia", "tetraplegia", "wheelchair athletes" and "disabilities athletes" in combination with the terms "isometric strength", "handgrip" and "handheld", using the boolean operator "AND". In this phase the titles and abstracts of the articles were read.

In the second phase, two researchers ( $\mathrm{JL}$ and SO) carried out the full readings of the selected studies in order to identify the main information reported. After the previous two phases, the last phase aimed at evaluating the scientific authenticity criteria adopted for the selection of measurement equipment, and the construction of a table with the purpose of summarizing the selected studies, containing the following aspects: author, periodical, muscle group(s) tested, used equipment, related variables and the main findings.

\section{Criteria for selecting studies}

In order to be eligible for the full reading process, articles should have the following criteria: a) contain as sample people with $\mathrm{SCl}$, and may be characterized as paraplegia, tetraplegia, spina bifida or poliomyelitis; b) describe the methods of evaluation in detail, specifying the types, methods and used equipment for data collection; c) have been written in English, Portuguese or Spanish. In order not to be considered in the review process, the studies should present: a) inadequate descriptions of the sample or assessment methods of isometric strength; b) have been carried out using non-disabled persons or animals in experimental studies; c) review studies.

\section{Data analysis}

For data analysis, we chose to use an ordinal scale created by the researchers based on dichotomous criteria. The scale is based on the scientific authenticity criteria of objectivity, reproducibility, concurrent validity and ecological validity. ${ }^{(13,14)}$ An additional criterion was considered for the evaluation of articles related to the characterization of the tests with regard to regulatory standards. For each item on the scale, the numeral "0 (zero)" was given to those who did not have the information and the numeral " 1 (one)" to those who had it.

The final score of each study was given by the sum of all items on the evaluation scale. Studies which presented more information regarding the authenticity of the test procedures would be closer to the " 5 " score, while those with less information would be closer to the " 0 " score. After analyzing the criteria referenced and observed by the scale, we chose to divide the findings based on the existing relations with each addressed topic by the articles found after the searches.

\section{RESULTS}

A total of 22 studies were found after administration of established inclusion and exclusion criteria, with verification of adequacy to the subject in the reading of the title summary of the investigations. All the steps of the research are presented in figure 1.

After analyzing these manuscripts, it was observed that four other studies did not meet the established criteria. The steps of the search with the respective quantities of selected articles are arranged in the flowchart. Regarding the criteria selected by the authors, the distribution of the analyzed studies according to the scientific authenticity criteria used is presented in Table 1. 


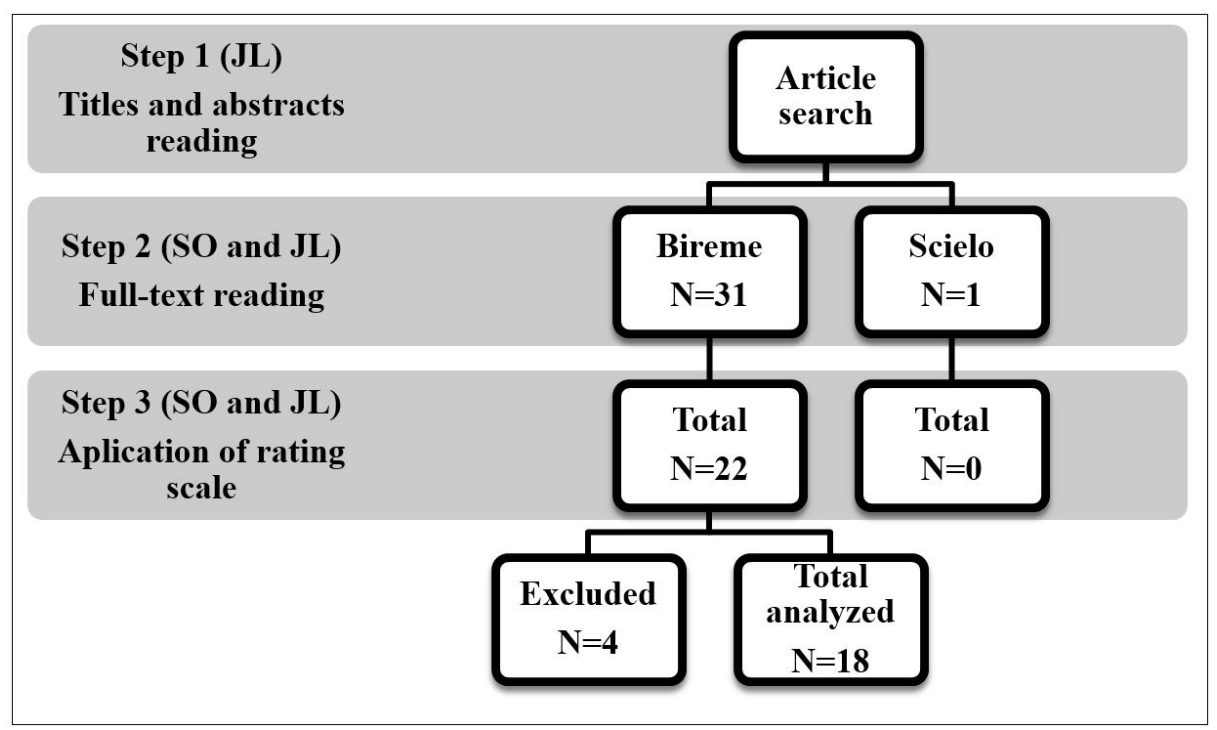

Figure 1. Flowchart of research steps

Table 1. Proportion of studies reporting scientific authenticity criteria for evaluation procedures

\begin{tabular}{ccc} 
Criteria & Articles $(\mathbf{N})$ & Percentage frequency of articles (\%) \\
Objectivity & 1 \\
Reproducibility & 4 \\
concurrent validity & 0 \\
Ecological validity & 18.67 \\
Normative standardization & 0.00 \\
\hline
\end{tabular}

As it is possible to note, among the evaluated criteria the ecological validity was the one which presented a greater number of related studies. Regarding 18 investigations, 10 presented information which relates to the functional characteristics of people with $\mathrm{SCl}$, especially considering the muscular groups and movements of the wheelchair propulsion. Three studies presented indications of reproducibility of evaluation procedures.

Only two studies reported information regarding objectivity and normative standardization. For the criterion of concurrent validity, no studies reporting this characteristic were observed. Finally, it was decided to extract, as main information, the data referring to: a) author; b) periodic; c) muscle group; d) used equipment; e) correlated variables/types of lesions; and f) main findings. The details of the topics are presented in table 2.

\section{DISCUSSION}

Due to the characterization of the localized investigations, it was verified that the main topics of interest related to the assessment of isometric strength in people with $\mathrm{SCl}$ are related to the following themes: a) isometric strength, physical activity and health of people with $\mathrm{SCl}$; $\mathrm{B}$ ) special resources for assessment of strength in people with $\mathrm{SCl}$; and c) the hemodynamic responses in isometric contraction protocols. Thus, we will try to present the main arguments and interpretations coming from the selected studies after the search.

\section{Isometric strength, physical activity, and health of people with $\mathrm{SCl}$}

Nooijen et $\mathrm{al}^{(7)}$ studied the relationship between the level of daily activity and lipid profile in people with a recent $\mathrm{SCl}$. $A$ handheld dynamometer was used to measure maximum isometric force. The authors verified that the used equipment (handheld dynamometer, brand Biometrics Europe BV, Almere) can not evaluate the lower forces by the sum of the reached scores through several muscle groups. They also verified that the physical activity level measured by accelerometry, oxygen consumption and lipid profile were not related to the isometric force measured by the dynamometer.

Davis et $\mathrm{al}^{(15)}$ documented the extending and aerobic detraining result in $\mathrm{SCl}$, examining the potential to reverse these changes through arm ergometer training during 16 weeks. The handheld dynamometer was used at $30 \%$ of the isometric force for 3 minutes at the wrist joint. At the end of the intervention, the isometric force was significantly decreased after 8 to 16 weeks, and the left ventricular mass, 
Table 2. Summary of selected and evaluated studies after inclusion criteria administration.

\begin{tabular}{|c|c|c|c|c|c|c|}
\hline Authors & Periodic & Muscle/Joint Group & Equipment & $\begin{array}{l}\text { Related variables/ } \\
\text { lesion type }\end{array}$ & Main findings & Score \\
\hline $\begin{array}{l}\text { Carla F.J. Nooijen } \\
\text { (2012) }\end{array}$ & Spinal Cord & $\begin{array}{l}\text { Flexors and elbow } \\
\text { extensors; Flexors, } \\
\text { external rotators and } \\
\text { shoulder abductors. } \\
\text { They were evaluated on } \\
\text { both sides }\end{array}$ & $\begin{array}{l}\text { Handheld dynamometer } \\
\text { (Biometrics Europa BV, } \\
\text { Almere) }\end{array}$ & $\begin{array}{l}\text { Physical activity } \\
\text { level measured by } \\
\text { accelerometry, oxygen } \\
\text { consumption and } \\
\text { lipid profile; Groups } \\
\text { of paraplegics and } \\
\text { quadriplegics }\end{array}$ & $\begin{array}{l}\text { Hand dynamometer can not } \\
\text { evaluate all lower forces by } \\
\text { summing the scores of five specific } \\
\text { muscle groups. }\end{array}$ & 1 \\
\hline
\end{tabular}

\begin{tabular}{|c|c|c|c|c|}
\hline $\begin{array}{l}\text { Nancy L. Black } \\
\text { (2007) }\end{array}$ & $\begin{array}{l}\text { Applied } \\
\text { Ergonomics }\end{array}$ & Shoulder, arm and wrist & $\begin{array}{l}\text { Computerized } \\
\text { measuring system } \\
\text { (CISMS) }\end{array}$ & $\begin{array}{l}\mathrm{NA} \text {; Paraplegics and } \\
\text { people without } \mathrm{SCl}\end{array}$ \\
\hline
\end{tabular}

The CISMS has the unique positioning capability in exact locations of entire range of the upper limbs and allows continuous adjustments in relation to vertical. Comparing levels of absolute force with isometric strength, paraplegic adults have 30\% "push up" strength and 51\% "pull down" strength.

The elbow moment transducer has proven to be a useful and reliable measurement tool. It is easily $\begin{array}{llll}\text { W. D. Menberg } & \text { Clinical } & \text { The elbow moment } & \text { NR } \\ \text { (2001) } & \text { Biomechanics }\end{array} \quad \begin{aligned} & \text { specific transducer }\end{aligned}$ mounted on any of arms and requires minimal adjustments. It may be used to quantify isometric moments produced over a wide range of elbow positions.

Hand grip dynamometry has great potential, and could be used more

\begin{tabular}{|c|c|}
\hline Manuel Rosety- & Brazilian \\
\hline $\begin{array}{l}\text { Rodriguez } \\
\text { (2014) }\end{array}$ & $\begin{array}{l}\text { Journal of } \\
\text { Urology }\end{array}$ \\
\hline
\end{tabular}
(2014) Urology
Electronic Handheld dynamometer (Jamar metro Bolingbrook, Illinois, USA)
Arm ergometer, body composition and blood samples; Paraplegic people frequently in clinical practice in a wide range of medical conditions. Regarding the evaluation of muscle strength, the maximum manual grip strength significantly improved after the completion of the specific intervention program.

Blood pressure increases little in non-fatiguing contractions and

Jerrold Scott European Petrofsky Journal of (2001) Applied Physiology
Handheld dynamometer and a functional electric stimulation leg dynamometer.
Heart rate and blood pressure; Tetraplegic and paraplegic people with complete and incomplete lesion. remains elevated at the end of a fatiguing isometric contraction when occlusion is applied to the active limb. Slow dynamic exercise causes similar changes in heart rate and blood pressure as in isometric exercise.

Blood pressure (systolic and diastolic) of paraplegics with hypertension were higher at $20 \%, 40 \%, 60 \%, 80 \%$ or $100 \%$ of maximal voluntary contraction, when compared to the other two non-deficient groups. During the isometric manual tension exercise, 0 blood pressure had a higher BP in the hypertensive group than the other two groups, however lower than the exercise of electric stimulation in the leg. The heart rate modestly increased in the fatiguing isometric contraction.

Heart rate and blood pressure; People with with simultaneous electrical stimulation hypertensive and non-hypertensive paraplegias
(2000)
Applied

Physiology
Quadriceps and wrist

Legend: NR: non-reported; Paraplegia/paraplegic: thoracic SCl; Tetraplegia/tetraplegic: cervical SCI. 
Table 2. Continued

\begin{tabular}{|c|c|c|c|c|c|c|}
\hline Authors & Periodic & Muscle/Joint Group & Equipment & $\begin{array}{l}\text { Related variables/ } \\
\text { lesion type }\end{array}$ & Main findings & Score \\
\hline $\begin{array}{l}\text { Stephen P. Burns } \\
\text { (2005) }\end{array}$ & $\begin{array}{l}\text { Archives } \\
\text { of Physical } \\
\text { Medicine and } \\
\text { Rehabilitation }\end{array}$ & $\begin{array}{l}\text { Biceps and triceps } \\
\text { brachial on both sides }\end{array}$ & Handheld dynamometer & NA; Tetraplegic people & $\begin{array}{l}\text { During the use of the manual } \\
\text { dynamometer the greater force } \\
\text { is registered faster, and the } \\
\text { differences in the angular velocity } \\
\text { may be explained by the magnitude } \\
\text { measures of the evaluated force. } \\
\text { The angular velocity variation is a } \\
\text { potential source of dynamometer } \\
\text { variability in a series of force } \\
\text { measurements. }\end{array}$ & 1 \\
\hline $\begin{array}{l}\text { Glen M. Davis } \\
\text { (1987) }\end{array}$ & $\begin{array}{l}\text { European } \\
\text { Journal of } \\
\text { Applied } \\
\text { Physiology } \\
\text { and } \\
\text { Occupational } \\
\text { Physiology }\end{array}$ & Wrist & Handheld dynamometer & $\begin{array}{l}\text { Maximum power, heart } \\
\text { rate, maximum oxygen } \\
\text { consumption, cardiac } \\
\text { output and arterial } \\
\text { pressure; Paraplegic } \\
\text { people and without SCl }\end{array}$ & $\begin{array}{l}\text { Mass, dimensions and indices of } \\
\text { left ventricle performance were } \\
\text { unchanged at resting or during the } \\
\text { isometric handgrip. Rates of BP } \\
\text { increase during isometric hand-grip } \\
\text { strength tests decreased significantly } \\
\text { after } 8 \text { and } 16 \text { weeks of training and } \\
\text { physical fitness. }\end{array}$ & 0 \\
\hline $\begin{array}{l}\text { SF Hobbs } \\
(1985)\end{array}$ & $\begin{array}{l}\text { Neuroscience } \\
\text { Letters }\end{array}$ & Wrist & Handheld dynamometer & $\begin{array}{l}\text { Heart rate and blood } \\
\text { pressure; Paraplegic } \\
\text { people and without } \mathrm{SCl}\end{array}$ & $\begin{array}{l}\text { Systolic pressure increased } \\
\text { significantly during sessions of } \\
\text { isometric contractions when } \\
\text { evaluated for paraplegic people with } \\
\text { rheumatic heart disease }\end{array}$ & 0 \\
\hline $\begin{array}{l}\text { Patrick Freund } \\
\text { (2011) }\end{array}$ & $\begin{array}{l}\text { Brazilian a } \\
\text { journal of } \\
\text { neurology }\end{array}$ & Wrist & $\begin{array}{l}\text { hand-grip strength using } \\
\text { magnetic resonance } \\
\text { imaging }\end{array}$ & $\begin{array}{l}\text { Bilateral function of the } \\
\text { upper limb; Tetraplegic } \\
\text { people and without SCI }\end{array}$ & $\begin{array}{l}\text { During movements of isometric } \\
\text { contraction, there was an increase } \\
\text { in the volume of gray matter, in } \\
\text { the area corresponding to left } \\
\text { leg, of primary motor cortex and } \\
\text { improvement of the motor function. }\end{array}$ & 0 \\
\hline $\begin{array}{l}\text { Meegan G. Van } \\
\text { Straaten } \\
(2014)\end{array}$ & $\begin{array}{l}\text { Archives } \\
\text { of Physical } \\
\text { Medicine and } \\
\text { Rehabilitation }\end{array}$ & $\begin{array}{l}\text { Retractors, depressants } \\
\text { and external rotators of } \\
\text { the scapula }\end{array}$ & $\begin{array}{l}\text { Telerrehabilitation } \\
\text { exercise program. }\end{array}$ & $\begin{array}{l}\text { NR; Paraplegic people, } \\
\text { tetraplegic and post- } \\
\text { polio }\end{array}$ & $\begin{array}{l}\text { The isometric strength } \\
\text { measurement in scapular retractors } \\
\text { increased after exercise, no } \\
\text { difference for inferior trapezius, } \\
\text { rotators and abductors at } 12 \text { weeks } \\
\text { of intervention. }\end{array}$ & 2 \\
\hline $\begin{array}{l}\text { Serra-Añó } \\
\text { (2012) }\end{array}$ & Spinal Cord & Shoulder & $\begin{array}{l}\text { Isokinetic dynamometer } \\
\text { (Biodex System, Biodex } \\
\text { Medical Systems, Inc., } \\
\text { New York, NY, USA). }\end{array}$ & $\begin{array}{l}\text { Fat-free mass of the } \\
\text { arms and the thoracic } \\
\text { region and evaluation } \\
\text { of pain during daily } \\
\text { activities; Paraplegic } \\
\text { people }\end{array}$ & $\begin{array}{l}\text { There was a significant increase in } \\
\text { the isometric and isokinetic strength } \\
\text { of several shoulder movements, } \\
\text { a decrease in arm fat mass, and a } \\
\text { decrease in reported shoulder pain } \\
\text { after an exercise period of eight } \\
\text { weeks. }\end{array}$ & 1 \\
\hline $\begin{array}{l}\text { Biman Das } \\
(2000)\end{array}$ & $\begin{array}{l}\text { International } \\
\text { Journal of } \\
\text { Occupational } \\
\text { Safety and } \\
\text { Ergonomics }\end{array}$ & $\begin{array}{l}\text { The right arm making the } \\
\text { pull and push movement } \\
\text { (chest, back and } \\
\text { shoulder) }\end{array}$ & $\begin{array}{l}\text { Force Sensor Transducer } \\
\text { (MLP200, Durham } \\
\text { Instruments, Canada) }\end{array}$ & $\begin{array}{l}\text { Anthropometric } \\
\text { measurements of } \\
\text { upper limbs and trunk; } \\
\text { Paraplegic people }\end{array}$ & $\begin{array}{l}\text { The average male pulling force was } \\
25 \% \text { higher than that of pushing; } \\
\text { And the female was } 77 \% \text { higher; } \\
\text { The force of pushing was similar } \\
\text { between men and women differing } \\
\text { only in the degree of asymmetry; } \\
\text { The women were stronger at } \\
\text { pushing in the frontal plane, while } \\
\text { the men were stronger at a } 45^{\circ} \\
\text { forward angle. This may be due to a } \\
\text { decrease in stability associated with } \\
\text { the narrower chairs used by women } \\
\text { than men. }\end{array}$ & 1 \\
\hline $\begin{array}{l}\text { Christopher } \\
\text { M. Powers } \\
(1994)\end{array}$ & $\begin{array}{l}\text { Arch Phys } \\
\text { Med Rehabil }\end{array}$ & Shoulder & $\begin{array}{l}\text { Isokinetic dynamometer } \\
\text { (Lido brand) }\end{array}$ & $\begin{array}{l}\text { NR; Paraplegic and } \\
\text { tetraplegic people }\end{array}$ & $\begin{array}{l}\text { The torque in the quadriplegic } \\
\text { group was significantly lower } \\
\text { than the paraplegic groups for the } \\
\text { motions tested; This indicates that } \\
\text { quadriplegics may be at greater risk } \\
\text { for this shoulder pathology due to } \\
\text { muscle limitation and increased } \\
\text { physiological demand. The mean } \\
\text { value of internal rotation torque } \\
\text { for quadriplegic and paraplegic } \\
\text { patients was considered lower than } \\
\text { the mean value of the non-disabled } \\
\text { group. }\end{array}$ & 1 \\
\hline
\end{tabular}

Legend: NR: non-reported; Paraplegia/paraplegic: thoracic SCl; Tetraplegia/tetraplegic: cervical SCI. Post-polio: post-polio syndrome 
Table 2. Continued

\begin{tabular}{|c|c|c|c|c|c|c|}
\hline Authors & Periodic & Muscle/Joint Group & Equipment & $\begin{array}{l}\text { Related variables/ } \\
\text { lesion type }\end{array}$ & Main findings & Score \\
\hline $\begin{array}{l}\text { Sandra L. Stevens } \\
\text { (2013) }\end{array}$ & $\begin{array}{l}\text { Top Spinal } \\
\text { Cord Inj } \\
\text { Rehabil }\end{array}$ & $\begin{array}{l}\text { Hip (abduction, flexion } \\
\text { and extension), } \\
\text { knee (flexion and } \\
\text { extension), ankle } \\
\text { dorsiflexion and } \\
\text { plantar flexion }\end{array}$ & $\begin{array}{l}\text { Handheld dynamometer } \\
\text { (J-Tech Medical, } \\
\text { Salt Lake City, Utah) }\end{array}$ & $\begin{array}{l}\text { Resistance and } \\
\text { preferred walking } \\
\text { speed; Paraplegic and } \\
\text { quadriplegic people, } \\
\text { both incomplete }\end{array}$ & $\begin{array}{l}\text { Efforts to improve the behavior } \\
\text { of people with } \mathrm{SCl} \text { (incomplete } \\
\text { injury to the spinal cord) should } \\
\text { be directed toward increased } \\
\text { resistance and walking speed. }\end{array}$ & 3 \\
\hline $\begin{array}{l}\text { Thomas W.J. } \\
\text { Janssen } \\
\text { (2002) }\end{array}$ & $\begin{array}{l}\text { Journal of } \\
\text { Rehabilitation } \\
\text { Research and } \\
\text { Development }\end{array}$ & Arm & $\begin{array}{l}\text { Ergometer for } \\
\text { wheelchairs }\end{array}$ & $\begin{array}{l}\text { A sprint test, } \\
\text { physiological } \\
\text { measures, maximum } \\
\text { power and BMl; } \\
\text { Paraplegic, tetraplegic } \\
\text { people and } \\
\text { poliomyelitis }\end{array}$ & $\begin{array}{l}\text { The measured isometric force } \\
\text { indicates that predictive equations } \\
\text { must be used with care, and that } \\
\text { objective and direct measures } \\
\text { of physical capacity must be } \\
\text { preserved; also indicate that a } \\
\text { low physical capacity may lead } \\
\text { to fatigue or inability to perform } \\
\text { certain daily activities. }\end{array}$ & 2 \\
\hline $\begin{array}{l}\text { Jerrold Scott } \\
\text { Petrofsky } \\
\text { (2002) }\end{array}$ & $\begin{array}{l}\text { Eur J Appl } \\
\text { Physiol }\end{array}$ & wrist and quadriceps & $\begin{array}{l}\text { Tensometric and } \\
\text { isometric transducer; } \\
\text { Handheld dynamometer }\end{array}$ & $\begin{array}{l}\text { Strength, resistance, } \\
\text { blood pressure and } \\
\text { heart rate responses; } \\
\text { Paraplegic people }\end{array}$ & $\begin{array}{l}\text { The heart rate response to an } \\
\text { isometric contraction of manual } \\
\text { grip decreases by about } 50 \% \\
\text { between the ages of } 20 \text { and } 60 \text { in } \\
\text { paraplegics; In the tests performed } \\
\text { on the quadriceps muscle the } \\
\text { heart rate changes somewhat in } \\
\text { the paraplegics during contractions } \\
\text { by electrical stimulation; Blood } \\
\text { pressure increased for all groups } \\
\text { linearly to a final value of 50\% of } \\
\text { resting pressure after contractions } \\
\text { of the wrist muscle until fatigue. } \\
\text { Blood pressure was higher in } \\
\text { fatiguing leg length compared to } \\
\text { isometric manual grip exercise, } \\
\text { but these differences were not } \\
\text { significant at any assessed ages. }\end{array}$ & 0 \\
\hline $\begin{array}{l}\text { Sharon Gabison } \\
(2014)\end{array}$ & $\begin{array}{l}\text { The Academy } \\
\text { of Spinal } \\
\text { Cord Injury } \\
\text { Professionals }\end{array}$ & Trunk and hip & $\begin{array}{l}\text { Handheld dynamometer } \\
\text { (MicroFET 2, Hoggan } \\
\text { Saúde Indústrias, West } \\
\text { Jordan, UT, EUA). }\end{array}$ & $\begin{array}{l}\text { Maximum static } \\
\text { resistance of the } \\
\text { upper and lower } \\
\text { trunk extremities, } \\
\text { and the range of } \\
\text { motion of the trunk } \\
\text { (upper and lower } \\
\text { extremity); People } \\
\text { with myelopathy, } \\
\text { osteomyelitis, } \\
\text { osteoporosis, } \\
\text { arteriovenous } \\
\text { malformation, } \\
\text { medullary } \\
\text { compression, equine } \\
\text { tail and spinal stenosis }\end{array}$ & $\begin{array}{l}\text { There was a significant increase } \\
\text { in trunk strength measurements } \\
\text { throughout the rehabilitation } \\
\text { period in traumatic and non- } \\
\text { traumatic } \mathrm{SCl} \text { patients, both for } \\
\text { walkers and for wheelchair users; } \\
\text { on the other hand, significant } \\
\text { differences were found in hip } \\
\text { strength between walkers and } \\
\text { wheelchair users at the time of } \\
\text { admission. }\end{array}$ & 2 \\
\hline
\end{tabular}

Legend: NR: non-reported; Paraplegia/paraplegic: thoracic SCI; Tetraplegia/tetraplegic: cervical SCI.

dimensions and performance indices were unchanged after isometry training. The findings suggest that, in order to cause significant cardiovascular changes through isometric training, large muscle masses should be stimulated at the level of the trunk and other sites of the upper limbs of people with $\mathrm{SCl}$.

In a similar study, Rosety-Rodriguez et al. ${ }^{(8)}$ analyzed that the 12-week effect of an arm ergometer protocol on reproductive hormone levels (testosterone, estradiol, FSH) in
$\mathrm{SCl}$ people also evaluated the influence of the protocol on the muscular strength and body composition of the participants. The maximum isometric force was measured by the handheld dynamometer, with a significant improvement in manual grip strength. Regarding the evaluated hormones, only testosterone showed significant increases after the training period.

Burns et al. ${ }^{(16)}$ desired to determine the relationship between the force measured with handheld dynamometer, 
the obtained angular velocity during the testing protocol, in addition to possible differences in different angular speeds. These velocities were measured by an electrogoniometer (figure 2). The force was measured during the peak period using a handheld dynamometer, applying it to the biceps and triceps brachii. At the end of the experiments, it was concluded that the angular velocity variation is a potential source of variability in tests using the handheld dynamometer, in a series of force measurements. Larger angular velocities provide higher values of muscle strength, probably due to the contribution of the stretching-shortening cycle. ${ }^{(10,11)}$ Depending on the variable and the purpose of the test, larger or smaller angular velocities should be chosen.

In the context of clinical neurology, Freund et al. ${ }^{(17)}$ investigated the relationship between brain morphology as measured by MRI of the brain, and neurological functional elements of the subject. Among the functional variables analyzed together, we aslo attempted to find relationships with isometric strength. A protocol of voluntary contraction of $30 \%$ of CVM was used in the wrist joint with the handheld dynamometer, in conjunction with magnetic resonance imaging. It was concluded that there was an increase in gray matter volume in the left leg area of the primary motor cortex and improvement of motor function; those neurological information from the motor cortex is related to a greater capacity to generate isometric strength by people with different levels of $\mathrm{SCl}$.

From the point of view of intervention, Straaten et al. ${ }^{(3)}$ analyzed how an isometric intervention could reduce pain and improve the functions of trained muscles. It was used for tele-rehabilitation exercise program (rehabilitation through home exercise with the use of information in video media), and checked the peak strength in shoulder muscles retractors, depressants and external shoulder rotators. It was concluded that the measure of isometric strength in scapular retractors increased after the exercise period; no difference was observed

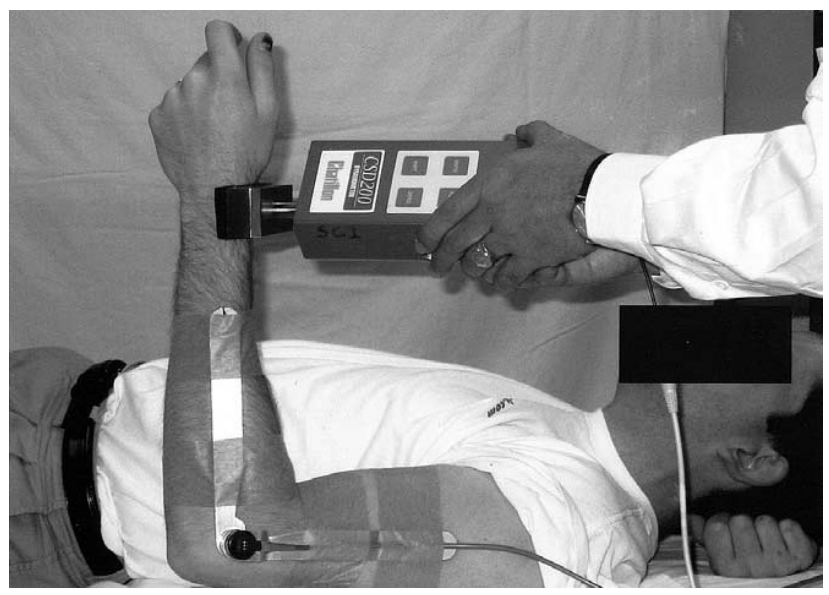

Figure 2. Diagram showing the apparatus for checking the angular velocities in tests with handheld dynamometer. Photo by Burns et al (2005). for the lower trapezius muscles, rotators and abductors after 12 weeks of training.

In another intervention study, Sierra-Year et al. ${ }^{(6)}$ studied the effects on body composition, pain feeling and functionality in paraplegic of an endurance training program on the shoulder using isokinetic and isometric force as stimulation. An isokinetic dynamometer was used for each flexion, extension, abduction, adduction and rotation of shoulder and only for every five seconds, followed by a 30 seconds recovery, performing a concentric contraction. It was concluded that the training produced a significant increase in isometric strength and isokinetic of several various movements of the shoulder, decrease of the arm fat mass, a decrease in reported pain in the shoulder and improvement of all standardized form tested movements. These findings are very important in view of the relationship between health shoulders and functionality in people with $\mathrm{SCl}$, especially those dependent on manual wheelchairs for locomotion.

From the ergonomic point of view, Biman et al. ${ }^{(18)}$ aimed at determining isometric force paraplegic profiles to assist in ergonomic designs related to workstations. It was used a force transducer which measured the maximum isometric strength of the right arm, performing the movements of pushing and pulling. It was concluded that the male pulling force (average) was $25 \%$ greater than the pushing force, against $77 \%$ difference between women; pushing force was similar between men and women differing only the degree of asymmetry (angle and direction of the applied force).

Regarding the focus on the functional levels of isometric force, Powers et al. ${ }^{(5)}$ compared strength deficits in people with varying levels of $\mathrm{SCl}$, documenting the shoulder weakness of this population. Through an isokinetic dynamometer, it was calculated the isometric torque of internal rotation, external and elevation of the shoulders, in a protocol of 30 seconds with abduction and adduction. It was concluded that the torque from the quadriplegia group (quadriplegics) was significantly lower than the group of movements tested for paraplegics, confirming that the quadriplegic may have greater risk for diseases by overusing the joint shoulders.

Stevens et al. ${ }^{(19)}$ quantified the relationship between lower resistance, walking speed and daily activity in people with incomplete $\mathrm{SCl}$ (not wheelchairs dependent); an ancillary manner, with these results, they wanted to determine the best measure for daily physical activity. A handheld dynamometer was used to measure the maximum isometric force the abduction, hip flexion and extension, knee flexion and extension and ankle dorsiflexion (illustrative model of figure 3). Finally, it was concluded that future efforts to improve the behavior of these $\mathrm{SCl}$ should be directed towards increasing muscular strength of the extremities (arms and legs) of the body, and also regarding the walking speed. The results also point to the necessity to adapt the power measures the 
functionality of the test subjects, including those who have injured even moderate motor performance levels.

Janssen et al. ${ }^{(1)}$, defined rules and determining values of physical performance in people with paraplegia and tetraplegia. The maximum power of arm was tested, from the estimation of isometric force equations in an ergometer wheelchair specially built for this purpose. It was found that estimated values of isometric force should be used with care, and that the physical capacity measurements performed by direct and objective procedures must be preserved, even for people with physically active $\mathrm{SCl}$.

Finally, Gabison et al. ${ }^{(20)}$ investigated the differences in the trunk strength and sitting range between walkers and wheelchair users; additionally they explored the differences between strength of the regions of trunk and hip. For force measurements, it was used a handheld dynamometer, with the capability of generating maximum torque of trunk and hip. The authors concluded that there is significant increase in strength measures the trunk along the rehabilitation of patients with traumatic and non-traumatic SCl. This increase occurs in both groups (walkers and wheelchair users); On the other hand, significant differences were found in the hip force between walkers and wheelchair users at admission, indicating major changes in the functionality of these regions even in early rehabilitation programs.

\section{Special features for strength evaluating in people with SCI}

Black $^{(21)}$ described the design, development, construction and testing protocols of a computerized measuring system, focusing on accuracy during use. A computerized system for measuring isometric force was used, by means of pulleys and transducers, with the possibility of adapting various functional movements of wheelchair users, with application

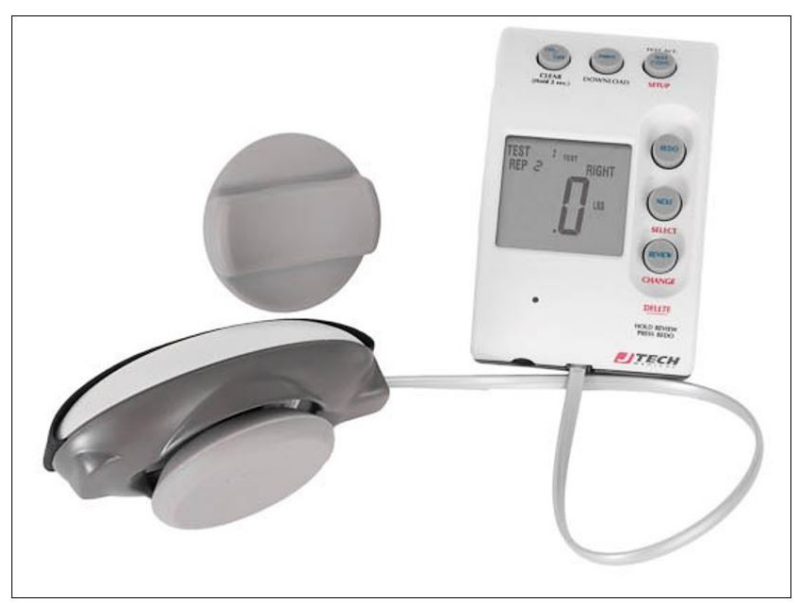

Figure 3. Illustrative photo of a typical dynamometer to evaluate the strength in different planes, axes and movements. Source: Photo by the company website. focus on regions of the shoulder, arm and wrist (Figure 4). The authors found that comparing the absolute isometric forces the paraplegic adults have 30\% strength "push it up" and $51 \%$ of the force to "pull down" compared to adults who do not have $\mathrm{SCl}$.

In the same perspective, Memberg et al. ${ }^{(22)}$ designed and programmed a transducer for accurately measuring the isometric moments of the elbow produced by individuals with quadriplegia. To measure the isometric force, it was used a special equipment to assess the moment force of the elbow joint (Figure 5). The results showed that the device may be used to quantify isometric moments produced by different elbow positions, in which it becomes a useful tool for functional evaluation of strength in individuals with $\mathrm{SCl}$.

\section{Isometric strength tests and hemodynamic responses in people with $\mathrm{SCI}$}

In order to verify the hemodynamic responses in the evaluation sessions of isometric strength, Petrofsky ${ }^{(23)}$ found how the blood pressure and heart rate respond to isometric exercise. It was used the handheld dynamometer to measure the wrist maximum force, and to measure the strength of quadriceps, it was used an electrical stimulation causing contraction to $40 \%$ of maximum isometric contraction. It was

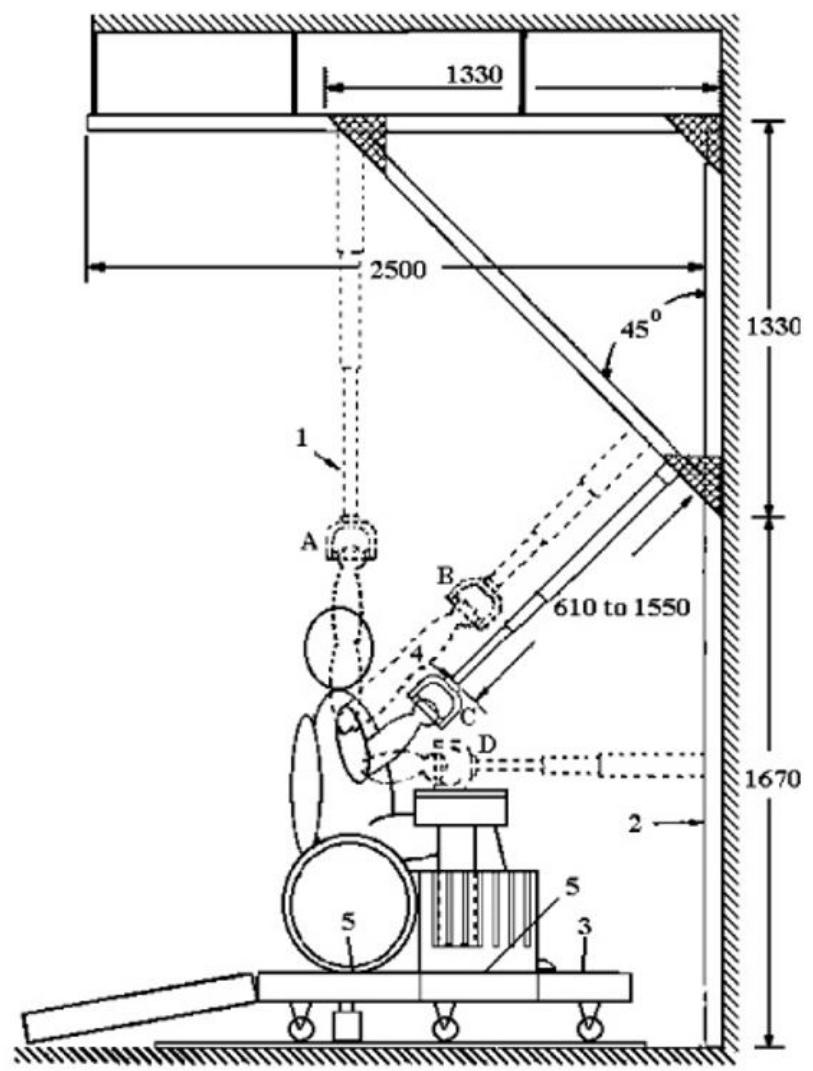

Figure 4. Equipment built for strength evaluation in different planes. Retrieved from Black \& Das (2007). 
concluded that the blood pressure rises slightly during the not-stressful contractions and remains high at the end of a stressful isometric contraction. On the other hand, the slow dynamic exercise as well as isometric exercise causes similar changes in heart rate and blood pressure. In another similar study, the same authors [Petrofsky ${ }^{(24)}$ ] compared the response of blood pressure (BP) which occurs during isometric exercise in hypertensives paraplegics and non-hypertensive individuals. It was found that the BP remains high only for subjects with $\mathrm{SCl}$ who have some previous autonomic dysfunction and that resonates in important changes in the BP. The same effect is not expected at $\mathrm{SCl}$ people which do not have autonomic uncontrolled at the level of blood pressure.

Also in this sense, Petrofsky ${ }^{(25)}$ examined the relationship between age, paraplegia, strength, resistance, blood pressure and heart rate responses to stressful isometric exercise. It was used an isometric transducer in the quadriceps to $40 \%$ of maximum muscle strength and a handheld dynamometer to measure the maximum voluntary contraction of the wrist. It was concluded that isometric force about $50 \%$ between 20 and 60 years in paraplegics through the isometric contraction handgrip; in isometric contractions of the quadriceps to the level heart rate suffers little change; however, the blood pressure increased in all groups linearly to a final value of $50 \%$ of the resting blood pressure.

In a similar study focusing on blood pressure, Hobbs ${ }^{(26)}$ analyzed the variation of the pressure response in the handheld dynamometer tests the level of manual wrist joint, to quantitate any differences in cardiovascular response. It was concluded that systolic pressure increased significantly during these contractions when evaluated in paraplegic people with rheumatic heart disease, making it more prone public to present major changes of systolic blood pressure during strength exercises or assessment procedures through maximal isometric contractions.

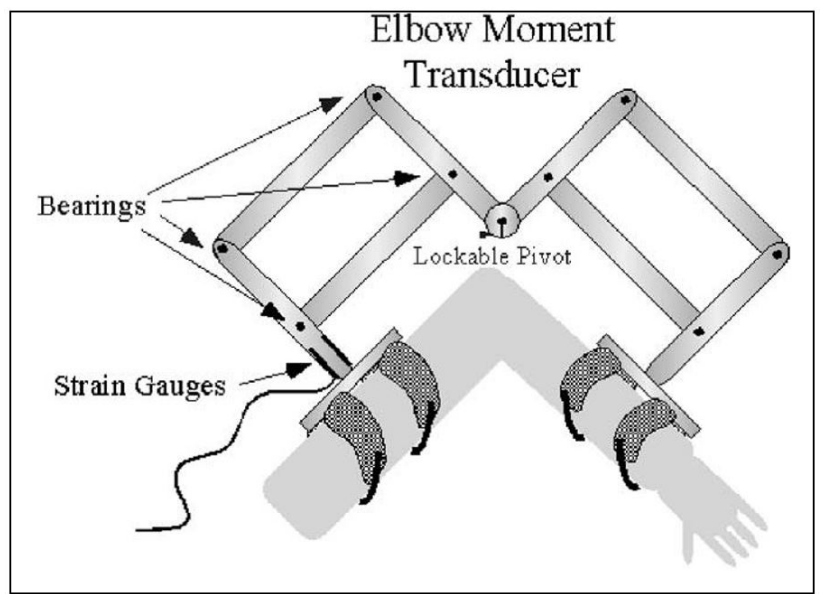

Figure 5. Illustration of a device (transducer) specially constructed for evaluation of force/moment of the shoulders. Taken from Menberg et al. (2001)

\section{CONCLUSIONS}

We conclude that the methods/equipment used by the specialized literature are handheld dynamometer, isokinetic dynamometer and other computerized measuring systems through force transducers specially designed for this purpose. Isometric strength of people with $\mathrm{SCl}$ was sensitive and susceptible to improvements promoted by rehabilitation programs following the injury. However, the most prone area to such modification was the shoulder joint. This improvement was also extended to the isokinetic strength of several movements in the same joint. On the other hand, it was found that quadriplegic people may be at greater risk for diseases in this region.

By using sophisticated equipment, paraplegics have an absolute and isometric strength of the movement "push it up" higher; otherwise strength values related to motion "pull down" are smaller compared to those which do not have SCl, which indicate the relationship between level of the lesion and neurological impairment. Regarding to interactions with hemodynamic variables, it has been found that the blood pressure (systolic and diastolic) remains high at the end of an isometric contraction; this pressure was higher in the hypertensive group as well as during exercise with electrical stimulation.

On the other hand, heart rate decreases during the handgrip force movement, which may be interpreted as a cardioprotective effect in the evaluation in sessions or even training in people with $\mathrm{SCl}$, which suggest the non-occurrence of cardiovascular complications in this population.

Although most of the findings point to the handgrip as safe and valid assessment method, still remains a lack of standardization and regulatory frameworks for assessing isometric strength in this population. This information reinforces the necessity for further studies aiming patterning and these norms, with data collection in a representative sample of individuals with $\mathrm{SCl}$.

\section{AUTHORS' CONTRIBUTIONS:}

$\mathrm{JL}$ : delineation of the research, search/reading of the manuscripts, writing and results interpretation; SO: research design, writing and results interpretation; LO: writing and results interpretation; MC: research design and results interpretation.

\section{CONFLICTS OF INTEREST:}

The authors declare that there are no potential conflicts of interest.

\section{AUTHOR DETAILS}

${ }^{1}$ Specialist in Strength Training for Health, Escola Superior de Educação Física de Pernambuco, Recife (PE), Brazil.

${ }^{3}$ Specialist in Human Performance Assessment, student of the Associate Program of Post-Graduation in Physical Education, Universidade de Pernambuco/Universidade Federal de Pernambuco, Recife (PE), Brazil.

${ }^{4}$ Doctor of Sport Sciences, Escola Superior de Educação de Pernambuco, Recife (PE), Brazil. 


\section{REFERENCES}

1. Janssen TW, Dallmeijer AJ, Veeger D, \& van der Woude LH. Normative values and determinants of physical capacity in individuals with spinal cord injury. Journal of rehabilitation research and development. 2002;39(1):29.

2. O’Sullivan S, Schmitz T. Fisioterapia: avaliação e tratamento. Manole; 2004.

3. Van Straaten MG, Cloud BA, Morrow MM, Ludewig PM, Zhao KD. Effectiveness of home exercise on pain, function, and strength of manual wheelchair users with spinal cord injury: a high-dose shoulder program with telerehabilitation. Arch Phys Med Rehabil. 2014; 95(10):1810-7.e2

4. Mercer JL, Boninger M, Koontz A, Ren D, Dyson-Hudson T, Cooper R. Shoulder joint kinetics and pathology in manual wheelchair users. Clin Biomech (Bristol, Avon). 2006;21(8):781-9.

5. Powers CM, Newsam CJ, Gronley JK, Fontaine CA, Perry J. Isometric shoulder torque in subjects with spinal cord injury. [Internet]. Archives of physical medicine and rehabilitation. 1994; p. 761-5.

6. Serra-Añó P, Pellicer-Chenoll M, García-Massó X, Morales J, Giner-Pascual M, González L-M. Effects of resistance training on strength, pain and shoulder functionality in paraplegics. Spinal Cord [Internet]. International Spinal Cord Society; 2012;50(11):827-31.

7. Nooijen CFJ, de Groot S, Postma K, Bergen MP, Stam HJ, Bussmann $J B J$, et al. A more active lifestyle in persons with a recent spinal cord injury benefits physical fitness and health. Spinal Cord. 2012;50(4):320-3.

8. Rosety-Rodriguez M, Rosety I, Fornieles G, Rosety JM, Elosegui S, Rosety MA, et al. A short-term arm-crank exercise program improved testosterone deficiency in adults with chronic spinal cord injury. Int Braz J Urol. 2014;40(3):367-72

9. Sisto SA, Dyson-Hudson T. Dynamometry testing in spinal cord injury. J Rehabil Res Dev. 2007;44(1):123-36.

10. Hall S. Biomecânica Básica. Rio de Janeiro: Guanabara Koogan; 2003.

11. Hamill. Bases Biomecânicas do Movimento Humano. Barueri: Manole; 1999.

12. Marciello MA, Herbison GJ, Ditunno JFJ, Marino RJ, Cohen ME. Wrist strength measured by myometry as an indicator of functional independence. J Neurotrauma. 1995;12(1):99-106.

13. Thomas J, Nelson J, Silverman S. Métodos de pesquisa em atividade física. 2002nd ed. Artmed, editor. Artmed; 2002.
14. Guedes DP. Manual prático para avaliação em educação física. São Paulo: Manole; 2005.

15. Davis GM, Shephard RJ, Leenen FHH. Cardiac effects of short term arm crank training in paraplegics: echocardiographic evidence. Eur J Appl Physiol Occup Physiol. 1987;56(1):90-6.

16. Burns P, Kressler J, Nash MS. Physiological Responses to Exergaming After Spinal Cord Injury. Top Spinal Cord Inj Rehabil [Internet]. 2012;18(4):3319.

17. Freund P, Weiskopf N, Ward NS, Hutton C, Gall A, Ciccarelli O, et al. Disability, atrophy and cortical reorganization following spinal cord injury. Brain [Internet]. 2011;134(Pt 6):1610-22.

18. Das B, Black NL. Isometric pull and push strengths of paraplegics in the workspace: 1 . Strength measurement profiles. Int J Occup Saf Ergon. 2000;6(1):47-65.

19. Stevens SL, Fuller DK, Morgan DW. Leg strength, preferred walking speed, and daily step activity in adults with incomplete spinal cord injuries. Top Spinal Cord Inj Rehabil [Internet]. 2013;19(1):47-53.

20. Gabison S, Verrier MC, Nadeau S, Gagnon DH, Roy A, Flett HM. Trunk strength and function using the multidirectional reach distance in individuals with non-traumatic spinal cord injury. J Spinal Cord Med [Internet]. 2014;37(5):537-47.

21. Black NL, Das B. A three-dimensional computerized isometric strength measurement system. Appl Ergon. 2007;38(3):285-92.

22. Memberg WD, Murray WM, Ringleb SI, Kilgore KL, Snyder SA. A transducer to measure isometric elbow moments. Clin Biomech. 2001;16(10):918-20.

23. Petrofsky JS. Blood pressure and heart rate response to isometric exercise: the effect of spinal cord injury in humans. Eur J Appl Physiol [Internet]. 2001;85(6):521-6.

24. Petrofsky JS, Laymon M. Blood pressure and heart rate responses during a fatiguing isometric exercise in paraplegic men with hypertension. Eur J Appl Physiol. 2000;83(4-5):274-82.

25. Petrofsky J, Laymon M. The effect of ageing in spinal cord injured humans on the blood pressure and heart rate responses during fatiguing isometric exercise. 2002; Eur J Appl Physiol [Internet]. 86(6):479-86.

26. Hobbs SF, Gandevia SC. Cardiovascular responses and the sense of effort during attempts to contract paralysed muscles: role of the spinal cord. Neuroscience letters. 1985;57(1):85-90. 